\title{
Digital Panoramic Radiography in Dental Age Estimation
}

\author{
Maryam Kazemipoor $^{1(\mathbb{D})}$, Mohammad Nima Motallaei ${ }^{2, *}$ (D) Mahdieh Dehghani $^{3}$ (D) \\ 1 Department of Endodontic, Faculty of Dentistry, Shahid Sadoughi University of Medical Sciences, Yazd, Iran; \\ dr.kazemipoor@gmail.com (M.K.); \\ 2 Department of Endodontic, Faculty of Dentistry, Shahid Sadoughi University of Medical Sciences, Yazd, Iran; \\ nimamotallaei@gmail.com (M.N.M.); \\ 3 Department of Oral and Maxillofacial Radiology, Faculty of Dentistry, Shahid Sadoughi University of Medical Sciences, \\ Yazd, Iran; mdehghanit@yahoo.com (M.D.); \\ * Correspondence: nimamotallaei@gmail.com;
}

Scopus Author ID 57215831450

Received: 10.10.2020; Revised: 2.11.2020; Accepted: 4.11.2020; Published: 7.11.2020

\begin{abstract}
The present study aimed to assess the validity of coronal pulp/tooth area ratio (AR) and tooth/coronal index (TCI) indices in the mandibular first molar and second premolar for age estimation.110 digital panoramic radiographs of 60 male and 50 female subjects aged between 15 to 44 years were studied. The coronal pulp/tooth area ratio (AR) and tooth/crown index (TCI) of mandibular first molar and second premolar teeth was measured using AutoCAD software. Data were analyzed based on Pearson correlation coefficient regression formula and, t-test, and ANOVA. Considering the effect of sex, differences in the morphological variable of mandibular first molar and second premolar were not statistically significant. In the mandibular first molars, the subject's age significantly affects the AR (P-value $=0.003)$ and TCI $(\mathrm{P}$-value=0.027) indices. There was a significant and positive correlation between the two morphological variables of AR and TCI ( $\mathrm{r}=0.797$ for mandibular second premolar and $\mathrm{r}=0.0686$ for a mandibular first molar, $\mathrm{P}$-value $<0.001$ ). Linear regression analysis showed that concurrent application of the two indices in one formulation could be a reliable technique for age estimation. According to the results of this study, in the Iranian populations, the application of AR and TCI indices simultaneously in one formulation had better results for age estimation in younger adults.
\end{abstract}

Keywords: dental pulp; age determination by teeth; forensic dentistry; panoramic radiography panoramic.

(C) 2020 by the authors. This article is an open-access article distributed under the terms and conditions of the Creative Commons Attribution (CC BY) license (https://creativecommons.org/licenses/by/4.0/).

\section{Introduction}

Estimation determination of an individual's age is an important subject in forensic or legal content. In living people, age estimation is applied for the majority of determination estimations in case of kidnapping, rape, hiring, and marriage, in the cases where the date of birth is not clear, or criminal cases [1]. In dead bodies, age estimation is applied for aiding the identification of victims, criminals, and damaged bodies in accidents, fires, suicides, abortions, and murders [2].

In the human body, teeth are the hardest and most resistant organ against the structural changes that occurred during tissue disintegration [3]. Also, in comparison to the bone, tooth mineralization did not significantly affect by diseases, drugs, and endocrine status [4]. Therefore, teeth can be considered as a biological marker and an ideal tissue to use in forensic and archaeological research [5,6]. Dental age estimation is less variable in comparison with the skeletal age estimation and sexual maturity indices in the youth age [7]. Various methods have 
been proposed for chronological age estimation using dental tissues [2]. These methods are based on radiological, biochemical, histological, and morphological approaches [8]. Morphological and histological methods assessed dental wear, secondary dentin formation, gingival loss, cement deposition, and translucency of root dentin $[9,10]$. The biochemical method is also a newly introduced method that studies changes in the chemical composition of teeth [11-15]. Since the above-mentioned methods are invasive and warrant tooth extraction, they could be applied only in the dead bodies [16].

Radiography is a simple, non-invasive, and reliable method that applies to both living and dead bodies [2]. Radiological methods that are based on the calcification stages in developing teeth are not a suitable method in people over 25 years when calcification and development of the third molar have been terminated [17]. Radiographic dental age estimation in adults should be directed toward the dimensional changes that occurred in the tooth structure [3]. For dental age estimation, volumetric changes in the pulpal cavity because of secondary dentin deposition and pulp/tooth area ratio were reliable indices in adults [18-20].

Kvaal et al. [21] in 1995 introduced a radiographic method based on the measurement of pulpal length and width as well as root length and width. They concluded that there was a negative correlation between pulp/tooth width ratios and age. Cameriere et al. [22] measured the length, width, and area of pulp, root, and tooth in single-rooted maxillary canines. They concluded that there is the best correlation between pulp and tooth area ratio with the agepositive correlation between pulp and tooth area. Pulp to tooth ratios as reliable radiographic indices have been studied in various ethnic groups [23-26]. Most of the studies in this era have been evaluated canine teeth because of its single root and largest pulp chamber that makes the radiological measurements easier [17,27-30]. In the absence of canine teeth, other teeth could be considered as a substitution for dental age estimation [31-35]. Mathew et al. [36] made a method for dental age estimation by mandibular first molar tooth because of its large pulp chamber volume, and it's an easy distinction in panoramic images.

Mandibular second premolars are also studied due to the large crown volume and less overlap with adjacent teeth (compared to mandibular first premolar and maxillary premolars)mater [17]. Apposition of secondary dentine and tooth wear has been applied as indirect non-destructive indicators for age estimation. Secondary dentine apposition is measured as pulpal area and tooth wear as tooth area. Most of the studies calculated the tooth area instead of the coronal tooth area. Moreover, the two indices of area ratio and vertical indices in the coronal part of the tooth have not been applied in one formulation up to the present. This study was done to validate the combined application of coronal tooth indices in the mandibular first molar and second premolar for chronological age estimation.

\section{Materials and Methods}

\subsection{Experimental procedure.}

All the experimental procedures in the present study were following the Declaration of Helsinki and approved by the local ethics committee. 110 digital panoramic radiographs from a dental clinic belonged to patients of both sexes (60 males and 50 females) between the ages group of 15 and 44 years were studied in the present study. The samples were distributed into 3 age groups: 15-24 years, 25-34 years, and 35-44 years. The presence of left and right mandibular first molar and second premolar free from developmental or morphological abnormalities and good technical quality of a radiograph was set as the inclusion criteria. Teeth 
with restoration (i.e., amalgam restoration, crown), caries defect, rotation or inclination, excessive occlusal wear, and overlap with adjacent teeth and dental anomalies were excluded from the present survey. Also, patients with a history of any systemic diseases that affect the pulpal area and detection of its border (i.e., renal diseases) were not enrolled in the present study.

Standardized digital orthopantomography was taken with Planmeca radiographic unit (Proline, Planmeca, Finland) under the following conditions: voltage 66-70 KVP, intensity 8$10 \mathrm{~mA}$, and duration 10-12s. High-resolution radiographs were saved on a computer as JPEG files and then imported to AutoCAD software (Autodesk/AutoCAD version 2016, San Rafael, USA). The resolution of the monitor was $768666 * 13661366 * 768$ pixels.

All the measurements were done according to the identified points on the coronal tooth outline and the pulp periphery (Figure 1). We have used the AutoCAD zoom tool for a better view. In the presence of bilateral premolar and molar tooth, one-sided that pulpal cavity was barely visible seen was selected.

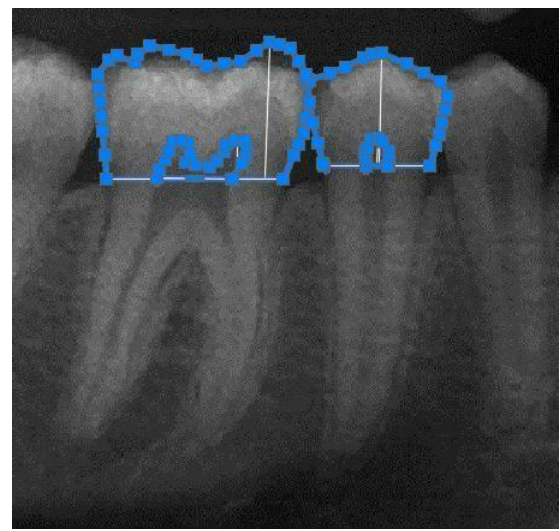

Figure 1. Estimation of tracing dots in the coronal segments of mandibular first molars and second premolars to measure AR and TCI indices. The points are marked with the point's option in AutoCAD software. Area option and distance option in AutoCAD software were also applied to measure the area of the pulp chamber and tooth and TCI index.

The reference points on the images of the mandibular first molar and second premolar teeth were defined. For vertical measurements, a cervical line was defined at the cementoenamel junction level. The crown height $(\mathrm{CH})$ was the maximum vertical interval from the highest point of the highest cusp to the cervical line, whereas the coronal pulp cavity height $(\mathrm{CPCH})$ was the vertical distance between the cervical line and highest pulp horn [37]. Tooth/crown index (TCI) was calculated for mandibular second premolars and molars as follows:

\section{$\mathrm{TCI}=\mathrm{CPCH} \times 100 / \mathrm{CH}$}

To measure the area of the tooth and pulp chamber in the second premolar and first molar 20 and 30 points on the outer surface of the crown and 10 and 20 points in the outer surface of the pulp were selected, respectively. All the tracings and measurements were done manually, and the tracing points were equally distributed along the outer surface of the tooth crown and dental pulp. Afterward, the defined points on the outlines of tooth and pulp were connected to calculate the area of the related tooth and pulp chambers. We have used area options in AUTOCAD software to measure the area of the pulp chamber cavity and tooth area. For the TCI index, we selected the points and use distance options to measure it. Pulp/tooth area ratio (AR) was defined as the proportion of coronal pulp area to the coronal tooth area. 
All the measurements were performed by the same investigator, who was blinded to the chronological age of the subjects, using image processing software (Autodesk/ AutoCAD 2016, USA). A random sample of 10 radiographs was reevaluated after the one-month interval to test the intra-observer reproducibility.

\subsection{Statistical analysis.}

Data were analyzed in SPSS ver.17 software (Spss Inc., Chicago, USA), and Pvalue $>0.05$ was considered significant. Pearson correlation coefficient and linear regression equations formulae according to observed age and predictive variables were calculated in the mandibular first molar and second premolar. The regression model to predict chronological age from AR and TCI of mandibular first molars and second premolars and both of the two indices in one formulation were developed. The Kolmogorov-Smirnov test confirmed the normal distribution of the data. Morphologic variables (AR, TCI) between males/females and the three age groups and the three age groups were analyzed using student t-test and ANOVA. Intra observer differences reproducibility of intra-examiner was determined by paired sample t-test.

\section{Results and Discussion}

In this study, 110 orthopantomography have been evaluated. Gender and age distribution of the groups are presented in Table1. Based on the paired sample t-test, there were no significant differences in intra-observer first and repeated measurements of images $(\mathrm{p}=0.0430)$.

Table 1. Gender and age distribution of the groups.

\begin{tabular}{c|c|c|c} 
Group & Age & Male & Female \\
\hline Group1 & $15-24$ & 19 & 21 \\
\hline Group 2 & $25-34$ & 22 & 17 \\
\hline Group 3 & $35-46$ & 19 & 12 \\
\hline Total & & 60 & 50
\end{tabular}

Table 2. Pearson's correlation between chronological age, pulp/tooth area ratio, and tooth/crown index in mandibular first molars and second premolars.

\begin{tabular}{c|c|c} 
Tooth & $\mathbf{r}$ & $\mathbf{p}$ \\
\hline Pearson's correlation between chronological age and TCI \\
\hline Second premolar & 0.087 & 0.363 \\
\hline First molar & 0.133 & 0.166 \\
\hline \multicolumn{2}{c}{ Pearson's correlation between chronological age and $\mathbf{A R}^{\mathbf{2}}$} \\
\hline Second premolar & -0.44 & 0.644 \\
\hline First molar & 0.051 & 0.600 \\
\hline Pearson's correlation between the pulp/tooth area ratio and tooth/crown index \\
\hline Second premolar & 0.797 & 0.000 \\
\hline First molar & 0.686 & 0.000 \\
1 & TCI: Tooth/crown index, ${ }^{2} \mathrm{AR}$ : Pulp/tooth area ratio
\end{tabular}

Considering the effect of sex, there were no significant differences in morphological variables of mandibular first molars and second premolars $(\mathrm{p}<0.05)$. In contrast, the subject's age significantly affects $\mathrm{AR}(\mathrm{P}=0.003)$ and TCI $(\mathrm{P}=0.027)$ indices in mandibular molar teeth. AR indices showed statistically significant differences between 25-34 and 16-24 age groups $(\mathrm{P}=0.004)$ and also $25-34$ and $35-46$ age groups $(\mathrm{P}=0.003)$. TCI indices showed statistically significant differences only between 25-34 and 35-46 age groups $(\mathrm{P}=0.009)$. Pearson's correlation coefficient showed a significant and positive correlation between the two morphological variables (AR and TCI) in both mandibular second premolar and molar teeth, 
respectively $(\mathrm{r}=0.797, \mathrm{p}=0.000)(\mathrm{r}=0.686, \mathrm{p}=0.000)$. In contrast, the correlation between age and TCI indices recorded positive and insignificant in both second premolar and molar teeth (Table2). There was also a negative and insignificant correlation between age and AR indices in the second premolars and a positive and insignificant correlation between age and AR index in the first molars (Table 2).

Linear regression analysis was carried out to estimate the chronological age based on AR and TCI indices in both mandibular second premolar and molar teeth(Table3). Based on the linear regression procedure, AR and TCI indices, when applied separately, are not valid variables to predict chronological age in both premolar and molar teeth. Oppositely, concurrent application of the two indices (AR and TCI) could be a useful, valid tool to predict chronologically. The regression equation when mandibular second premolar was taken into account was as follows:

\section{$\mathrm{AGE}=25.65-201 \times \mathrm{AR}+46.05 \times \mathrm{TCI}$}

The regression model for predicting chronological age using AR and TCI indices of mandibular first molar in one formulation was defined as:

$$
\mathrm{AGE}=24.128-34.657 \times \mathrm{AR}+26.844 \times \mathrm{TCI}
$$

Table 3. Regression analysis predicting chronological age using mandibular second premolars and first molars.

\begin{tabular}{|c|c|c|c|c|c|c|c|}
\hline \multirow{2}{*}{ Dent type } & \multirow[b]{2}{*}{ effect } & \multirow{2}{*}{$\begin{array}{l}\text { Regression } \\
\text { coefficient }\end{array}$} & \multirow{2}{*}{$\begin{array}{l}\text { Standard } \\
\text { error }\end{array}$} & \multirow[b]{2}{*}{$\mathbf{t}$} & \multirow{2}{*}{ p-value } & \multicolumn{2}{|c|}{$\begin{array}{c}95.0 \% \text { confidence interval } \\
\text { for the Regression coefficien }\end{array}$} \\
\hline & & & & & & $\begin{array}{l}\text { Lower } \\
\text { bound }\end{array}$ & Upper bound \\
\hline \multirow{3}{*}{$\begin{array}{l}\text { Mandibular } \\
\text { Second } \\
\text { Premolar } \\
\end{array}$} & Intercept & 25.65 & 2.65 & 9.681 & 0.000 & 20.399 & 30.901 \\
\hline & $\mathrm{AR}$ & -200.96 & 100.39 & -2.002 & 0.048 & -399.936 & -1.986 \\
\hline & TCI & 46.05 & 21.37 & 2.154 & 0.033 & 3.686 & 88.411 \\
\hline \multirow{3}{*}{$\begin{array}{l}\text { Mandibular } \\
\text { First Molar }\end{array}$} & Intercept & 24.13 & 3.33 & 7.236 & 0.000 & 17.518 & 30.739 \\
\hline & $\mathrm{AR}$ & -34.66 & 59.23 & -0.585 & 0.560 & -152.067 & 82.754 \\
\hline & TCI & 26.84 & 18.98 & 1.414 & 0.160 & -10.786 & 64.475 \\
\hline
\end{tabular}

Table 4 displays the mean difference between estimated and actual age using AR and TCI indices in mandibular first molars and second premolars.

Table 4. Mean \pm SD difference (years) between the actual and estimated age of the study population.

\begin{tabular}{c|c|c|c|c|c|c|c} 
& Category & Premolar & $\mathbf{0 . 9 5 \%} \mathbf{C I}$ & Sig & Molar & $\mathbf{0 . 9 5 \%} \mathbf{\text { I }}$ & Sig \\
\hline Using AR & Group1 & $-7.96 \pm 2.97$ & $-8.89-(-7.03)$ & 0.000 & $-8.57 \pm 2.47$ & $-9.36-(-7.78)$ & 0.000 \\
\cline { 2 - 8 } \& TCI & Group 2 & $0.15 \pm 2.71$ & $-0.7-1.03$ & 0.723 & $0.31 \pm 2.78$ & $-0.58-1.21$ & 0.484 \\
\cline { 2 - 8 } & Group3 & $10.59 \pm 4.09$ & $9.09-12.03$ & 0.000 & $10.66 \pm 3.63$ & $9.33-11.99$ & 0.000 \\
\hline \multirow{3}{*}{ Using AR } & Group1 & $-8.25 \pm 2.62$ & $-9.07-(-7.44)$ & 0.000 & $-6.13 \pm 2.49$ & $-6.93-(-5.34)$ & 0.000 \\
\cline { 2 - 8 } & Group 2 & $0.12 \pm 2.74$ & $-0.76-1.01$ & 0.777 & $2.26 \pm 2.83$ & $1.34-3.18$ & 0.000 \\
\cline { 2 - 8 } & Group3 & $11.05 \pm 3.56$ & $9.74-12.35$ & 0.000 & $13.42 \pm 3.56$ & $12.11-14.73$ & 0.000 \\
\hline \multirow{2}{*}{ Using } & Group1 & $-3.63 \pm 2.73$ & $-4.48-(-2.78)$ & 0.000 & $0.52 \pm 2.91$ & $-0.40-1.45$ & 0.261 \\
\cline { 2 - 8 } TCI & Group 2 & $4.73 \pm 2.90$ & $3.79-5.68$ & 0.000 & $8.74 \pm 3.10$ & $7.74-9.75$ & 0.000 \\
\cline { 2 - 8 } & Group3 & $15.82 \pm 3.67$ & $14.47-17.17$ & 0.000 & $20.30 \pm 3.75$ & $18.92-21.68$ & 0.000
\end{tabular}

When the two indices were applied in one formulation, the lowest mean difference between estimated and actual best results for age estimation was observed in group 2 (25-34 years). The mean difference between the actual and estimated age was $0.15 \pm 2.71$ for mandibular second premolar and $0.31 \pm 2.78$ for a mandibular first molar. In the application of AR indices, the lowest mean difference best results were recorded for group 2 (25-34 years) when mandibular second premolar was taken into account $(0.12 \pm 2.74)$.

Considering TCI indices, the lowest mean difference best results were observed in group 1 (15-24 years) when mandibular first molars were traced (0.52 2.91$)$. Dental hard tissue is the strongest structure in the body. Therefore, dental age estimation with less variability gained popularity in comparison to other skeletal and sexual maturity indicators $[38,39]$. 
Tooth formation and its stages of development have been widely used for chronological age estimation [8]. After the finalization of tooth development, the apposition of secondary dentin and reduction in pulp chamber volume and area can be considered as a reliable biomarker for dental age estimation [23]. In 1925, Bodecher investigated the correlation between secondary dentin appositions with age [37]. Dental radiographs, in comparison to morphological and histological methods, are a simple, non-destructive, and reproducible method for scientific dental age estimation from fully developed teeth [8]. In the present study, the coronal pulp/tooth area ratio (AR) and tooth/crown index (TCI) in the mandibular first molar and second premolar teeth have been measured in 110 digital panoramic radiographs to determine chronological age in an Iranian population. Secondary dentin deposition using conventional full mouth intraoral periapical radiographs has been introduced by Kvaal et al. [21] in 1995. Application of Kvaal indices in digital intraoral periapical radiographs showed large errors in age estimation [40]. In 2005, Bosmans et al.[41] have applied Kvaal's technique on digital orthopantomography. Panoramic radiographs have been routinely taken in dental examinations and made the assessment of full mouth in a single radiograph possible. Furthermore, digital panoramic images acquired with a standard technique have high reproducibility and is not technique sensitive [17]. In posterior mandibular teeth, the extent of the coronal pulp cavity is easily visible in OPGs and rendering of coronal pulp indices applied for age estimation this technique is mainly suitable for posterior mandibular teeth $[42,43]$.

Application of the ratio of variables instead of absolute measurements of variables in radiographic evaluation excludes the possible errors derived from different scales in $\mathrm{x}$-ray images [44]. Cameriere et al. [22] applied the pulp/tooth area ratio for age estimation, and this method has been tested on different teeth. In 1985, the coronal pulp cavity's length as a toothcoronal index (TCI) and its relation with chronological age had been introduced by Ikeda et al. [45]. In 1993, Drusini et al. [42,44] measured the coronal index (through the Ikeda et al. method) of premolars and molars to estimate age in unknown bodies and isolated teeth. In the present study, the $\mathrm{CPCH}$ was determined as a vertical line from the highest point of the highest pulp horn to the cervical line (according to Ikeda et al. 1985), and the $\mathrm{CH}$ was determined as a vertical line from the highest point of the highest cusp to the cervical line (according to Moss et al. 1967) [42,45].

In the present study, all the measurements have been done in the coronal part of the tooth. Based on a study by Drusini et al. [42], the strength of the correlation measurements in dental x-rays is higher in comparison to root dentin transparency in the same population. Kvaal's technique also measures the root dentin indices, and based on the published studies, the regression formulas proposed by Kvaal et al. directed to overestimation or underestimation of age and is not a reliable method to estimate age even on digital OPGs sample [37,46-48].

According to the present study, gender had no statistically significant influence on the examined indices in the mandibular first molar and second premolar. This findings finding is similar to the results of the studies on canine teeth $[17,46]$ and also studies on TCI index in mandibular premolars and molars [42,49]. In contrast, Agematsu et al. [50] in Japan and Igbigbi and Nyirenda [51]Malawi recorded that gender has a statistically significant effect on age estimation using TCI. Racial and cultural factors have also impact age estimation, and the validity of each method for age estimation should be examined in the different populations [52].

Validation of coronal area ratio and TCI index for age estimation in the Iranian population has not been studied up to the present. In the present study, the regression formula 
for age estimation gave better results when the two indices (AR and TCI) have been used concurrently. The mean difference among estimated and actual age using AR and TCI indices concurrently in second premolars and first molars of mandible gave a more precise result in group 2 (25-34 years), respectively $(0.15 \pm 2.71$ and $0.31 \pm 2.78)$. When AR indices were applied, better results were recorded in group 2 and mandibular second premolars $(0.12 \pm 2.74)$. The accuracy of TCI indices for age estimation was better when mandibular first molars in group 1 (15-24 years) were analyzed (0.52 \pm 2.91$)$. In comparison to mandibular premolars, mandibular molars have morphological diversity and less visibility in radiographs. Therefore the dimensional changes in the pulp chamber are not clear in molars [49].

Moreover, the pulp cavity upper limits of molars are sometimes less visible in the panoramic radiography that leads to difficulties in the TCI measurements $[49,51,53]$. According to Saxena et al. [52] study, accurate measurement of AR, and TCI indices in multirooted teeth are difficult to perform [52].

Drusini et al. [42] confirmed that the $\mathrm{CPCH}$ had a significant correlation with chronological age. The pattern of secondary dentin deposition varies in different tooth types [9]. In molar teeth, the greatest dentin deposition is on the pulp chamber's base and smaller volumes on the occlusal and lateral walls [9]. Considering the results of the present study, in mandibular molar teeth, there were significant differences between the three age groups (considering AR and TCI indices). AR index in the 25-34 age group showed a significant reduction in comparison to the other two age groups. It seems that in the 25-34 age duration, the pulp area decreases significantly. AR index in the 35-46 age group increased, therefore about the decrease in the area of the pulp chamber, the crown area should be decreased for the elevation of the AR index in the 35-46 age group. Crown area reduction may be the result of higher attrition incidence that occurred in the 35-46 age duration. TCI index showed a significant reduction between the 25-34 and 35-46 age groups. Similarly to the AR index in the 25-34 age group, the height of the pulp chamber and in the 35-46 age group, the crown height (as a consequence of attrition) has decreased. Many studies have evaluated the effect of side (either right or left teeth) and concluded that the difference between teeth side is not significant for age estimation $[44,49]$. In the present study, based on the visibility of the pulp chamber in the corresponding teeth, one side has been selected and measured. Similar to other studies $[2,17,54]$ in the present study, the intra-observer difference was not statistically significant between the repeated measurements. Pearson's correlation coefficient among morphological variables (AR and TCI) and the age of the second premolar and first molar showed an insignificant and positive correlation. Oppositely, the correlation coefficient between the two indices ((AR and TCI) showed a significant correlation. The mentioned results suggested the application of two indices simultaneously for age estimation. In the present survey only in mandibular second premolars, the regression equations gave better results when the two indices have been applied concurrently. The application of AR and TCI indices in one formulation could be a helpful and precise technique in the 25-34 age range. In this age range, tooth development and skeletal maturation have been completed and are not valid predictors for age estimation. Moreover, regular apposition of secondary dentin in this age period, in comparison to older adults, leads to more precise and delicate measurements of AR and TCI indices [17,55].

A limitation of the present study was the characteristic of a panoramic radiograph that made the detecting of reference points, especially in mandibular first molar, very difficult. The application of high-quality digital OPGs has partially decreased measurement errors during the examination. Designing and implementing image analysis software to detect the reference 
points automatically could minimize the errors of manual measurement. Moreover, characters of the studied population like genetic and racial differences, sample size, and examined teeth should be taken into consideration.

\section{Conclusions}

Within the limitations of this study, it seems that the application of different AR and TCI indices of mandibular first molars and second premolars in one formulation may be a useful technique for chronological age estimation in Iranian young adults (25-34 years). It is recommended to design and apply image analyzing software to define the reference points automatically and reduce technical errors. Also, designing and implementing an intelligent system for age estimation using dental panoramic images could help the clinician for precise age estimation could promote.

\section{Funding}

This research was funded by Shahid Sadoughi University of medical sciences, 5382.

\section{Acknowledgment}

The authors wish to give thanks to Shahid Sadoughi University of medical sciences for sponsoring this research.

\section{Conflicts of Interest}

None declared.

\section{References}

1. Maber, M.; Liversidge, H.M.; Hector, M.P. Accuracy of age estimation of radiographic methods using developing teeth. Forensic Sci. Int. 2006, 159 Suppl 1, S68-73, https://doi.org/10.1016/j.forsciint.2006.02.019.

2. Jagannathan, N.; Neelakantan, P.; Thiruvengadam, C.; Ramani, P.; Premkumar, P.; Natesan, A.; Herald, J.S.; Luder, H.U. Age estimation in an Indian population using pulp/tooth volume ratio of mandibular canines obtained from cone beam computed tomography. J. Forensic Odontostomatol. 2011, 29, 1-6.

3. Marroquin, T.Y.; Karkhanis, S.; Kvaal, S.I.; Vasudavan, S.; Kruger, E.; Tennant, M. Age estimation in adults by dental imaging assessment systematic review. Forensic Sci. Int. 2017, 275, 203-211, https://doi.org/10.1016/j.forsciint.2017.03.007.

4. Fins, P.; Pereira, M.L.; Afonso, A.; Perez-Mongiovi, D.; Caldas, I.M. Chronology of mineralization of the permanent mandibular second molar teeth and forensic age estimation. Forensic Sci. Med. Pathol. 2017, 13, 272-277, https://doi.org/10.1007/s12024-017-9876-3.

5. Shah, P.H.; Venkatesh, R. Pulp/tooth ratio of mandibular first and second molars on panoramic radiographs: An aid for forensic age estimation. J. Forensic Dent. Sci. 2016, 8, 112, https://doi.org/10.4103/09751475.186374.

6. Fernandez-Escudero, A.C.; Legaz, I.; Prieto-Bonete, G.; Lopez-Nicolas, M.; Maurandi-Lopez, A.; PerezCarceles, M.D. Aging and trace elements in human coronal tooth dentine. Sci. Rep. 2020, 10, 9964, https://doi.org/10.1038/s41598-020-66472-1.

7. Baccino, E.; Schmitt, A. Determination of Adult Age at Death in the Forensic Context. In Forensic Anthropology and Medicine: Complementary Sciences From Recovery to Cause of Death, Schmitt, A., Cunha, E., Pinheiro, J., Eds. Humana Press: Totowa, NJ, 2006; 259-280, https://doi.org/10.1007/978-159745-099-7_11.

8. Willems, G. A review of the most commonly used dental age estimation techniques. J. Forensic Odontostomatol. 2001, 19, 9-17.

9. Morse, D.R. Age-related changes of the dental pulp complex and their relationship to systemic aging. Oral Surg. Oral Med. Oral Pathol. 1991, 72, 721-745, https://doi.org/10.1016/0030-4220(91)90019-9.

10. Shah, J.S.; Ranghani, A.F.; Limdiwala, P.G. Age estimation by assessment of dentin translucency in permanent teeth. Indian J. Dent. Res. 2020, 31, 31-36, https://doi.org/10.4103/ijdr.IJDR_428_18. 
11. Adserias-Garriga, J.; Zapico, S. Age As-sessment in Forensic Cases: Anthropological, Odontological and Biochemical Methods for Age Estimation in the Dead. MJ Foren 2018, 1, 001.

12. Tahmasebi, E.; Alam, M.; Yazdanian, M.; Tebyanian, H.; Yazdanian, A.; Seifalian, A.; Mosaddad, S.A. Current biocompatible materials in oral regeneration: a comprehensive overview of composite materials. Journal of Materials Research and Technology 2020, 9, 11731-11755, https://doi.org/10.1016/j.jmrt.2020.08.042.

13. Soufdoost, R.S.; Mosaddad, S.A.; Salari, Y.; Yazdanian, M.; Tebyanian, H.; Tahmasebi, E.; Yazdanian, A.; Karami, A.; Barkhordari, A. Surgical Suture Assembled with Tadalafil/Polycaprolactone Drug-Delivery for Vascular Stimulation Around Wound: Validated in a Preclinical Model. Biointerface Research in Applied Chemistry 2020, 10, 6317-6327, https://doi.org/10.33263/briac105.63176327.

14. Soufdoost, R.S.; Yazdanian, M.; Tahmasebi, E.; Yazdanian, A.; Tebyanian, H.; Karami, A.; Nourani, M.R.; Panahi, Y. In vitro and in vivo evaluation of novel Tadalafil/ $\beta$-TCP/Collagen scaffold for bone regeneration: A rabbit critical-size calvarial defect study. Biocybernetics and Biomedical Engineering 2019, 39, 789-796, https://doi.org/10.1016/j.bbe.2019.07.003.

15. Shakeri, F.; Tebyanian, H.; Karami, A.; Babavalian, H.; Tahmasbi, M.H. Effect of Topical Phenytoin on Wound Healing. Trauma Monthly 2016, Inpress, e35488, https://doi.org/10.5812/traumamon.35488.

16. Priyadarshini, C.; Puranik, M.P.; Uma, S. Dental Age Estimation Methods-A Review; LAP Lambert Academic Publ: 2015.

17. Dehghani, M.; Shadkam, E.; Ahrari, F.; Dehghani, M. Age estimation by canines' pulp/tooth ratio in an Iranian population using digital panoramic radiography. Forensic Sci. Int. 2018, 285, 44-49, https://doi.org/10.1016/j.forsciint.2018.01.016.

18. Azevedo, A.C.; Michel-Crosato, E.; Biazevic, M.G.; Galic, I.; Merelli, V.; De Luca, S.; Cameriere, R. Accuracy and reliability of pulp/tooth area ratio in upper canines by peri-apical X-rays. Leg. Med. (Tokyo) 2014, 16, 337-343, https://doi.org/10.1016/j.legalmed.2014.07.002.

19. Andrade, V.M.; Fontenele, R.C.; de Souza, A.C.; Almeida, C.A.; Vieira, A.C.; Groppo, F.C.; Freitas, D.Q.; Junior, E.D. Age and sex estimation based on pulp cavity volume using cone beam computed tomography: development and validation of formulas in a Brazilian sample. Dentomaxillofac. Radiol. 2019, 48, 20190053, https://doi.org/10.1259/dmfr.20190053.

20. Verma, M.; Verma, N.; Sharma, R.; Sharma, A. Dental age estimation methods in adult dentitions: An overview. J. Forensic Dent. Sci. 2019, 11, 57-63, https://doi.org/10.4103/jfo.jfds_64_19.

21. Kvaal, S.I.; Kolltveit, K.M.; Thomsen, I.O.; Solheim, T. Age estimation of adults from dental radiographs. Forensic Sci. Int. 1995, 74, 175-185, https://doi.org/10.1016/0379-0738(95)01760-g.

22. Cameriere, R.; Ferrante, L.; Cingolani, M. Variations in pulp/tooth area ratio as an indicator of age: a preliminary study. J. Forensic Sci. 2004, 49, 317-319.

23. Cameriere, R.; De Luca, S.; Aleman, I.; Ferrante, L.; Cingolani, M. Age estimation by pulp/tooth ratio in lower premolars by orthopantomography. Forensic Sci. Int. 2012, 214, 105-112, https://doi.org/10.1016/j.forsciint.2011.07.028.

24. Zelic, K.; Pavlovic, S.; Mijucic, J.; Djuric, M.; Djonic, D. Applicability of pulp/tooth ratio method for age estimation. Forensic Sci. Med. Pathol. 2020, 16, 43-48, https://doi.org/10.1007/s12024-019-00200-8.

25. Valluri, R.; Jain, Y.; Lalitha, C.; Sajjan, P.; Ealla, K.K.R.; Dantu, R. Age Estimation in Mixed-dentition Children, Using Cameriere's European Formula and Demirjian's Method: A Comparative Pilot Study. J. Contemp. Dent. Pract. 2020, 21, 310-316.

26. Ribier, L.; Saint-Martin, P.; Seignier, M.; Paré, A.; Brunereau, L.; Rérolle, C. Cameriere's third molar maturity index in assessing age of majority: a study of a French sample. Int. J. Legal Med. 2020, 134, 783792, https://doi.org/10.1007/s00414-019-02123-z.

27. Yang, Z.; Fan, L.; Kwon, K.; Pan, J.; Shen, C.; Tao, J.; Ji, F. Age estimation for children and young adults by volumetric analysis of upper anterior teeth using CBCT data. Folia Morphol. (Warsz.) 2020, 10.5603/FM.a2020.0004, https://doi.org/10.5603/FM.a2020.0004.

28. Ubelaker, D.H.; Khosrowshahi, H. Estimation of age in forensic anthropology: historical perspective and recent methodological advances. Forensic sciences research $\mathbf{2 0 1 9}, 4, \quad 1-9$, https://doi.org/10.1080/20961790.2018.1549711.

29. Farhadian, M.; Salemi, F.; Saati, S.; Nafisi, N. Dental age estimation using the pulp-to-tooth ratio in canines by neural networks. Imaging Sci Dent 2019, 49, 19-26, https://doi.org/10.5624/isd.2019.49.1.19.

30. Kazmi, S.; Manica, S.; Revie, G.; Shepherd, S.; Hector, M. Age estimation using canine pulp volumes in adults: a CBCT image analysis. Int. J. Legal Med. 2019, 133, 1967-1976, https://doi.org/10.1007/s00414019-02147-5.

31. Zaher, J.F.; Fawzy, I.A.; Habib, S.R.; Ali, M.M. Age estimation from pulp/tooth area ratio in maxillary incisors among Egyptians using dental radiographic images. J. Forensic Leg. Med. 2011, 18, 62-65, https://doi.org/10.1016/j.jflm.2010.12.004.

32. Ilayaraja, V.; Ganapathy, N.; Jisha, G.; Keerthipriyadharshini, T.; Maheswaran, T.; Yoithapprabhunath, T.R. Digitized Morphometric Analysis using Maxillary Canine and Mandibular First Molar for Age Estimation in South Indian Population. The open dentistry journal 2018, 12, 762-769, https://doi.org/10.2174/1745017901814010762. 
33. Mwesigwa, C.L.; Kutesa, A.M.; Munabi, I.G.; Kabenge, C.A.; Buwembo, W. Accuracy of the lower third molar radiographic imaging to estimate age among Ugandan young people. BMC Res. Notes 2019, 12, 652, https://doi.org/10.1186/s13104-019-4686-1.

34. Zhang, Z.Y.; Yan, C.X.; Min, Q.M.; Li, S.Q.; Yang, J.S.; Guo, Y.C.; Jin, W.F.; Li, L.J.; Xing, P.F.; Li, J. Age estimation using pulp/enamel volume ratio of impacted mandibular third molars measured on CBCT images in a northern Chinese population. Int. J. Legal Med. 2019, 133, 1925-1933, https://doi.org/10.1007/s00414-019-02112-2.

35. Ashifa, N.; Parakh, M.K.; Ulaganambi, S. Estimation of Age Using Third Molar Development: A Radiological Cross-Sectional Study. Am. J. Forensic Med. Pathol. 2020, 41, 115-118, https://doi.org/10.1097/PAF.0000000000000540.

36. Mathew, D.G.; Rajesh, S.; Koshi, E.; Priya, L.E.; Nair, A.S.; Mohan, A. Adult forensic age estimation using mandibular first molar radiographs: A novel technique. J. Forensic Dent. Sci. 2013, 5, 56-59, https://doi.org/10.4103/0975-1475.114552.

37. Meinl, A.; Tangl, S.; Pernicka, E.; Fenes, C.; Watzek, G. On the applicability of secondary dentin formation to radiological age estimation in young adults. J. Forensic Sci. 2007, 52, 438-441, https://doi.org/10.1111/j.1556-4029.2006.00377.x.

38. Mani, S.A.; Naing, L.; John, J.; Samsudin, A.R. Comparison of two methods of dental age estimation in 715-year-old Malays. Int. J. Paediatr. Dent. 2008, 18, 380-388, https://doi.org/10.1111/j.1365263X.2007.00890.x.

39. Han, M.Q.; Chu, G.; Chen, T.; Zhou, H.; Guo, Y.C. Research Progress of Age Estimation Based on the Demirjian's Method. Fa yi xue za zhi 2019, 35, 737-743, https://doi.org/10.12116/j.issn.10045619.2019.06.017.

40. Sharma, R.; Srivastava, A. Radiographic evaluation of dental age of adults using Kvaal's method. J. Forensic Dent. Sci. 2010, 2, 22-26, https://doi.org/10.4103/0974-2948.71053.

41. Bosmans, N.; Ann, P.; Aly, M.; Willems, G. The application of Kvaal's dental age calculation technique on panoramic dental radiographs. Forensic Sci. Int. 2005, 153, 208-212, https://doi.org/10.1016/j.forsciint.2004.08.017.

42. Drusini, A.G.; Toso, O.; Ranzato, C. The coronal pulp cavity index: a biomarker for age determination in human adults. Am. J. Phys. Anthropol. 1997, 103, 353-363, https://doi.org/10.1002/(SICI)10968644(199707)103:3<353::AID-AJPA5>3.0.CO;2-R.

43. Gotmare, S.S.; Shah, T.; Periera, T.; Waghmare, M.S.; Shetty, S.; Sonawane, S.; Gite, M. The coronal pulp cavity index: A forensic tool for age determination in adults. Dent. Res. J. (Isfahan) 2019, 16, 160-165.

44. Drusini, A. The coronal pulp cavity index: A forensic tool for age determination in human adults. Cuadernos de medicina forense 2008, 14, 235-249, https://doi.org/10.4321/S1135-76062008000300006.

45. Ikeda, N.; Umetsu, K.; Kashimura, S.; Suzuki, T.; Oumi, M. [Estimation of age from teeth with their soft Xray findings]. Nihon Hoigaku Zasshi 1985, 39, 244-250.

46. Landa, M.I.; Garamendi, P.M.; Botella, M.C.; Aleman, I. Application of the method of Kvaal et al. to digital orthopantomograms. Int. J. Legal Med. 2009, 123, 123-128, https://doi.org/10.1007/s00414-008-0268-9.

47. Miranda, J.C.; Azevedo, A.C.S.; Rocha, M.; Michel-Crosato, E.; Biazevic, M.G.H. Age estimation in Brazilian adults by Kvaal's and Cameriere's methods. Brazilian oral research 2020, 34, e051, https://doi.org/10.1590/1807-3107bor-2020.vol34.0051.

48. Chandan, P.K.; Arora, K.S.; Das, M.; Kaur, P.; Mohaptra, S.; Pareek, S. Assessment of validity and reliability of Kvaal's method for age estimation among a population sample - A retrospective study. Indian J. Dent. Res. 2020, 31, 186-190, https://doi.org/10.4103/ijdr.IJDR_209_18.

49. El Morsi, D.; Rezk, H.; Aziza, A.; El-Sherbiny, M. Tooth coronal pulp index as a tool for age estimation in Egyptian population. J Forensic Sci Criminol 2015, 3, 1-8, https://doi.org/10.15744/2348-9804.2.501.

50. Agematsu, H.; Someda, H.; Hashimoto, M.; Matsunaga, S.; Abe, S.; Kim, H.J.; Koyama, T.; Naito, H.; Ishida, R.; Ide, Y. Three-dimensional observation of decrease in pulp cavity volume using micro-CT: agerelated change. Bull. Tokyo Dent. Coll. 2010, 51, 1-6, https://doi.org/10.2209/tdcpublication.51.1.

51. Igbigbi, P.S.; Nyirenda, S.K. Age estimation of Malawian adults from dental radiographs. West Afr. J. Med. 2005, 24, 329-333, https://doi.org/10.4314/wajm.v24i4.28227.

52. Saxena, S. Age estimation of indian adults from orthopantomographs. Brazilian oral research 2011, 25, 225229, https://doi.org/10.1590/s1806-83242011005000009.

53. Gok, E.; Fedakar, R.; Kafa, I.M. Usability of dental pulp visibility and tooth coronal index in digital panoramic radiography in age estimation in the forensic medicine. Int. J. Legal Med. 2020, 134, 381-392, https://doi.org/10.1007/s00414-019-02188-w.

54. Jeevan, M.B.; Kale, A.D.; Angadi, P.V.; Hallikerimath, S. Age estimation by pulp/tooth area ratio in canines: Cameriere's method assessed in an Indian sample using radiovisiography. Forensic Sci. Int. 2011, 204, 209 e201-205, https://doi.org/10.1016/j.forsciint.2010.08.017.

55. Molina, A.; Bravo, M.; Fonseca, G.M.; Marquez-Grant, N.; Martin-de-Las-Heras, S. Dental age estimation based on pulp chamber/crown volume ratio measured on CBCT images in a Spanish population. Int. J. Legal Med. 2020, https://doi.org/10.1007/s00414-020-02377-y. 